\title{
Platinum drug sensitivity and resistance in testicular germ cell tumors: two sides of the same coin
}

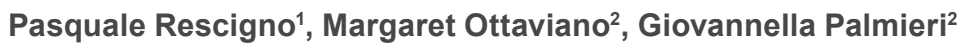 \\ 'Division of Clinical Studies, The Institute of Cancer Research and The Royal Marsden Hospital, London SM2 5NG, United \\ Kingdom. \\ ${ }^{2}$ Division of Oncology, CRTR Rare Tumors Reference Center, AOU Federico II, Naples 80100, Italy.
}

Correspondence to: Prof. Giovannella Palmieri, Head of the CRTR (Rare Tumors Reference Center), AOU Federico II of Naples, Via Pansini 5, Naples 80100, Italy. E-mail: giovpalm@unina.it How to cite this article: Rescigno P, Ottaviano M, Palmieri G. Platinum drug sensitivity and resistance in testicular germ cell
tumors: two sides of the same coin. Cancer Drug Resist2020;3:672-5. http://dx.doi.org/10.20517/cdr.2020.24

Received: 20 Apr 2020 Accepted: 30 Apr 2020 Available online: 16 Jun 2020

Science Editor: Frits Peters Copy Editor: Jing-Wen Zhang Production Editor: Jing Yu

Testicular germ cell tumors (TGCTs) represent the most common malignancies in young males but they also show the highest cure rate in solid tumors with more than $95 \%$ newly diagnosed TGCTs being ultimately cured $^{[1]}$.

Singh et al. ${ }^{[2]}$ recently provided precious insight into the genomic aberrations underpinning the molecular characteristics of these tumors and a clear presentation of the mechanisms underlying sensitivity/resistance to platinum.

More importantly, the authors identified pre-target, on-target and post-target factors that can explain, the two sides of the same coin: the exquisite sensitivity of these cancers to platinum-based chemotherapy and at the same time, drug resistance when these factors are lacking.

Nucleotide excision repair (NER) is the main DNA repair system aimed at resolving platinum-induced adducts. RNA polymerase II stalls at the site of DNA damage, resulting in the recruitment of cockayne syndrome type A and type B proteins (CSA and CSB) (ERCC8 and ERCC6). Therefore, inactivating mutations or deletions in key elements of the NER system result in responsiveness to cisplatin (CDDP), suggesting that a lack of DNA damage recognition and repair determines damage accumulation, which ultimately increases apoptosis in these cells ${ }^{[3]}$. Indeed, single-strand breaks can result in double-strand breaks that are repaired, under normal conditions, by the homologous recombination system, of which

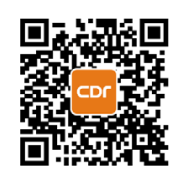


BRCA2 and PARP are essential components. Defects in the homologous recombination system can also be responsible for sensitivity to $\mathrm{CDDP}^{[4,5]}$.

The role of the mismatch repair (MMR) system in TGCTs still remains controversial, but potentially, it can open new treatment venues not particularly investigated by the authors in their review ${ }^{[2]}$.

In the context of defective NER, the MMR system is believed to detect DNA adducts caused by CDDP, engage in their repair and ultimately fail, thus transmitting a pro-apoptotic signal ${ }^{[6]}$.

Therefore, genes encoding MMR components such as mutS homolog 2 (MSH2) and mutL homolog 1 $(\mathrm{MLH1})$ are commonly mutated or downregulated in the context-acquired CDDP resistance in solid tumors $^{[7-9]}$.

MMR deficiency has been proposed as a biomarker of response to immune-checkpoint inhibitors ${ }^{[10,11]}$. While a phase II trial with pembrolizumab in unselected platinum-refractory TGCTs showed the absence of any clinical benefit ${ }^{[12]}$ and despite MMR deficiency being uncommon in primary tumors, approximately $25 \%$ of platinum-resistant TGCTs displayed a phenotype characterized by microsatellite instability and lack of expression of MLH1 or MSH6 ${ }^{[13]}$. Therefore, selecting platinum-refractory MMR-defective TGCTs could provide the right subset of patients likely to benefit from immune-checkpoint inhibition.

Lastly, Singh et al. ${ }^{[2]}$ discuss post-target and epigenetic causes of CDDP resistance in TGCTs, mainly focusing on $\mathrm{p} 53 / \mathrm{Mdm} 2$ alterations.

High MDM2 expression is associated with more advanced stages (IIB, IIC and III) and increased risk of metastatic disease in TGCTs ${ }^{[14,15]}$, and it seems to be induced by the activation of the PI3K/AKT pathway $^{[2]}$. These could represent new therapeutic targets, since MDM2 inhibitors ${ }^{[16]}$, as well as PI3K/AKT inhibitors ${ }^{[17]}$, are now under investigation as anticancer treatment in solid tumors. Moreover, several PI3K/ AKT inhibitors have shown synergistic or additive effects with CDDP against different cancer cells in vitro and in vivo experiments ${ }^{[18]}$.

The authors also pointed out that epigenetic modification such as DNA methylation may be associated with CDDP resistance ${ }^{[2]}$. Accordingly, seminomas, which are generally considered more CDDP sensitive, are severely hypomethylated, while embryonal carcinomas, which show some platinum resistance, have an intermediate level of methylation, and teratomas, yolk sac tumors and choriocarcinomas have the highest level of DNA methylation ${ }^{[2]}$.

The relevance of epigenetics opens two relevant avenues for the treatment and the follow-up of TGCTs.

The epigenetic agents guadecitabine (a prodrug of decitabine, a DNMT1 inhibitor), animacroxam (an HDAC inhibitor), and JQ1 (an inhibitor of the BET family of bromodomain proteins) have shown promising effects on TGCTs in preclinical in vivo and in vitro studies ${ }^{[19-21]}$.

Moreover, small noncoding RNAs that are involved in the epigenetic regulation of gene expression, such as microRNAs 371a-3p, were found to be highly sensitive and specific biomarkers for TGCTs ${ }^{[22]}$.

In conclusion, the work from Singh et al. ${ }^{[2]}$ not only reviews the main mechanism of resistance to platinumbased therapies in TGCTs, but also sheds light upon new therapeutic approaches. 


\section{DECLARATIONS}

\section{Authors' contributions}

Made substantial contributions to the conception of the manuscript and drafted the work: Rescigno P, Ottaviano M

Reviewed the manuscript critically: Palmieri G

\section{Availability of data and materials}

Not applicable.

\section{Financial support and sponsorship}

None.

\section{Conflicts of interest}

All authors declared that there are no conflicts of interest.

\section{Ethical approval and consent to participate}

Not applicable.

\section{Consent for publication}

Not applicable.

\section{Copyright}

(c) The Author(s) 2020.

\section{REFERENCES}

1. Einhorn LH. Treatment of testicular cancer: a new and improved model. J Clin Oncol 1990;8:1777-81.

2. Singh R, Fazal Z, Freemantle SJ, Spinella MJ. Mechanisms of sensitivity and resistance in testicular germ cell tumors. Cancer Drug Resist 2019;2:580-94

3. Galluzzi L, Vitale I, Michels J, Brenner C, Szabadkai G, et al. Systems biology of cisplatin resistance: past, present and future. Cell Death Dis 2014;5:e1257.

4. Cavallo F, Graziani G, Antinozzi C, Feldman DR, Houldsworth J, et al. Reduced proficiency in homologous recombination underlies the high sensitivity of embryonal carcinoma testicular germ cell tumors to Cisplatin and poly (adp-ribose) polymerase inhibition. PLoS One 2012;7:e51563.

5. Vaisman A, Varchenko M, Umar A, Kunkel TA, Risinger JI, et al. The role of hMLH1, hMSH3, and hMSH6 defects in cisplatin and oxaliplatin resistance: correlation with replicative bypass of platinum-DNA adducts. Cancer Res 1998;58:3579-85.

6. Aebi S, Kurdi-Haidar B, Gordon R, Cenni B, Zheng H, et al. Loss of DNA mismatch repair in acquired resistance to cisplatin. Cancer Res 1996;56:3087-90.

7. Drummond JT, Anthoney A, Brown R, Modrich P. Cisplatin and adriamycin resistance are associated with MutLalpha and mismatch repair deficiency in an ovarian tumor cell line. J Biol Chem 1996;271:19645-48.

8. Fink D, Aebi S, Howell SB. The role of DNA mismatch repair in drug resistance. Clin Cancer Res 1998;4:1-6.

9. Brown R, Hirst GL, Gallagher WM, McIlwrath AJ, Margison GP, et al. hMLH1 expression and cellular responses of ovarian tumour cells to treatment with cytotoxic anticancer agents. Oncogene 1997;15:45-52.

10. Le DT, Durham JN, Smith KN, Wang H, Bartlett BR, et al. Mismatch-repair deficiency predicts response of solid tumors to PD-1 blockade. Science 2017;357:409-13.

11. Rodrigues DN, Rescigno P, Liu D, Yuan W, Carreira S, et al. Immunogenomic analyses associate immunological alterations with mismatch repair defects in prostate cancer. J Clin Invest 2018;128:5185.

12. Adra N, Einhorn LH, Althouse SK, Ammakkanavar NR, Musapatika D, et al. Phase II trial of pembrolizumab in patients with platinum refractory germ-cell tumors: a Hoosier Cancer Research Network Study GU14-206. Ann Oncol 2018;29:209-14.

13. Honecker F, Wermann H, Mayer F, Gillis AJ, Stoop H, et al. Microsatellite instability, mismatch repair deficiency, and BRAF mutation in treatment-resistant germ cell tumors. J Clin Oncol 2009;27:2129-36.

14. Bagrodia A, Lee BH, Lee W, Cha EK, Sfakianos JP, et al. Genetic determinants of cisplatin resistance in patients with advanced germ cell tumors. J Clin Oncol 2016;34:4000-7.

15. Eid H, Institoris E, Géczi L, Bodrogi I, Bak M. Mdm-2 expression in human testicular germ-cell tumors and its clinical value. Anticancer Res 1999;19:3485-90. 
16. Wang S, Zhao Y, Aguilar A, Bernard D, Yang CY. Targeting the MDM2-p53 protein-protein interaction for new cancer therapy: progress and challenges. Cold Spring Harb Perspect Med 2017;7:a026245.

17. LoRusso PM. Inhibition of the PI3K/AKT/mTOR pathway in solid tumors. J Clin Oncol 2016;34:3803-15.

18. Avan A, Narayan R, Giovannetti E, Peters GJ. Role of Akt signaling in resistance to DNA-targeted therapy. World J Clin Oncol 2016;7:352-69.

19. Albany C, Hever-Jardine MP, von Herrmann KM, Yim CY, Tam J, et al. Refractory testicular germ cell tumors are highly sensitive to the second generation DNA methylation inhibitor guadecitabine. Oncotarget 2017;8:2949-59.

20. Jostes S, Nettersheim D, Fellermeyer M, Schneider S, Hafezi F, et al. The bromodomain inhibitor JQ1 triggers growth arrest and apoptosis in testicular germ cell tumours in vitro and in vivo. J Cell Mol Med 2017;21:1300-14.

21. Steinemann G, Dittmer A, Schmidt J, Josuttis D, Fähling M, et al. Antitumor and antiangiogenic activity of the novel chimeric inhibitor animacroxam in testicular germ cell cancer. Mol Oncol 2019;13:2679-96.

22. Nappi L, Thi M, Lum A, Huntsman D, Eigl BJ, et al. Developing a highly specific biomarker for germ cell malignancies: plasma miR371 expression across the germ cell malignancy spectrum. J Clin Oncol 2019;37:3090-98. 